\title{
Trabalho na Unidade Básica de Saúde: implicações para a qualidade de vida dos enfermeiros
}

\author{
Work in the Basic Health Unit: implications for nurses' quality of life
}

Trabajo en la unidad básico de salud: implicaciones para la calidad de vida de los enfermeros

\section{Greice Schrader', Sofia Palagi', Maria Angélica Silveira Padilha", Patrícia Tuerlinckx Noguez"', Maira Buss Thofehrn"', Daiane Dal Pai'"'}

I Universidade Federal de Pelotas, Curso de Enfermagem, Núcleo Estudos e Práticas de Enfermagem. Pelotas-RS, Brasil.

"Universidade Federal de Pelotas, Programa de Pós-Graduação em Enfermagem (Mestranda).

Universidade Federal de Pelotas, Hospital Escola. Pelotas-RS, Brasil.

II' Universidade Federal de Pelotas, Departamento de Enfermagem. Pelotas-RS, Brasil.

Submissão: 12-02-2011 Aprovação: 16-04-2012

\section{RESUMO}

Objetivou-se conhecer a percepção dos enfermeiros que atuam nas unidades básicas de saúde de Pelotas, Rio Grande do Sul, sobre a sua qualidade de vida no trabalho (QVT). Tratou-se de estudo qualitativo, exploratório e descritivo, realizado com sete enfermeiros por meio de entrevistas semiestruturadas. As falas dos participantes foram submetidas à análise temática. Condições inadequadas para o trabalho, desvalorização profissional e suporte insuficiente dos gestores foram categorias relacionados à baixa QVT, enquanto as relações interpessoais e a satisfação com a atividade de cuidar foram categorias relacionadas positivamente ao desempenho profissional e à QVT.

Descritores: Enfermagem; Centros de saúde; Condições de trabalho; Qualidade de vida.

\section{ABSTRACT}

The study aimed to know the perception of the nurses that work in the health basic units from Pelotas, Rio Grande do Sul, about their life quality in work (LQW). This is a qualitative, exploratory and descriptive study, carried out with seven nurses, through semi-structured interviews, submitted to thematic analysis. Inadequate conditions at work, professional belittling and insufficient support from the managers were categories related to low of low LQW meanwhile the interpersonal relations and the satisfaction with the activity of caring were categories positively related to professional performance and the LQW.

Key words: Nursing; Health centre; Working conditions; Quality of life.

\section{RESUMEN}

La investigación tuvo por objetivo conocer la percepción de los enfermeros que actúan en las unidades básicas de salud de Pelotas, Rio Grande do Sul, sobre su calidad de vida en el trabajo (CVT). Se trata de un estudio cualitativo, exploratorio y descriptivo, realizado con siete enfermeros por medio de entrevistas semiestructuradas. Los discursos de los participantes fueron sometidos a análisis temático. Condiciones inadecuadas para el trabajo, la desvalorización profesional y el soporte insuficiente de los gestores estaban relacionados con baja CVT baja, mientras que las relaciones interpersonales y la satisfacción con la actividad de cuidar se relacionaron positivamente con el desempeño laboral y de la CVT.

Palabras clave: Enfermería; Centro de salud; Trabajo; Calidad de vida. 


\section{INTRODUÇÃO}

A preocupação com a temática qualidade de vida no trabaIho tem adquirido dimensões significativas entre as pesquisas desenvolvidas nas ciências da saúde, uma vez que o trabalho tem sido considerado determinante na saúde dos indivíduos desde que o conceito de saúde deixou de estar atrelado exclusivamente à ausência de doença. A partir desse marco, a saúde deixa de ser um fenômeno isolado para resultar de diversas interações da vida com o meio ambiente em que a pessoa está inserida, o equilíbrio afetivo entre as pessoas, conhecimento do próprio corpo, solidariedade para com os outros, respeito, dentre outros ${ }^{(1)}$.

No que tange ao conceito de qualidade de vida, cabe mencionar que a Organização Mundial de Saúde (OMS) define qualidade de vida como a percepção do indivíduo quanto à sua posição na vida, tendo por base o contexto da sua cultura e do sistema de valores nos quais ele está inserido e em relação aos seus objetivos, expectativas, padrões e preocupações ${ }^{(2)}$.

Assim, o conceito de qualidade de vida conserva aspectos relevantes à individualidade e à subjetividade de cada sujeito com base no seu próprio julgamento pessoal. Deste modo, a qualidade de vida pode ser alcançada a partir da obtenção da satisfação e realização pessoal, profissional e social. Diante disso, o trabalho se torna elemento central para se pensar na qualidade de vida, porque é por meio dele que as pessoas têm procurado satisfazer suas aspirações ${ }^{(3)}$.

O conceito de Qualidade de Vida no Trabalho (QVT) passa por noções de motivação, satisfação, saúde e segurança no trabalho e envolve discussões sobre as novas formas de organização do trabalho e novas tecnologias ${ }^{(4)}$. Tendo isso em vista, pretende-se aqui focalizar o trabalho em saúde, com vistas ao questionamento acerca da qualidade de vida do profissional enfermeiro frente aos desafios colocados pelo processo de trabalho na atenção básica.

As unidades básicas de saúde têm sido locais caracterizados por diversos fatores que favorecem ou, até mesmo, dificultam a realização do trabalho do enfermeiro(5). Dessa forma, esses fatores, tais como valorização e reconhecimento profissional, educação permanente, vínculo estabelecido com a comunidade, trabalho conjunto com todos integrantes da equipe, falta de recursos humanos e de materiais e equipamentos, falta de compreensão e paciência da comunidade e dificuldades de relacionamento com os gestores. Ainda, fazem emergir nos trabalhadores sentimentos ambíguos com relação ao trabalho, com consequências de maior ou menor impacto sobre a vida cotidiana.

Desta forma, a compreensão dos elementos do processo de trabalho na enfermagem pode facilitar ao enfermeiro a conscientização de suas ações. O objeto de trabalho é o ser humano, sua família e a comunidade da área de atuação da equipe de saúde. A tarefa profissional, entendida como a própria execução do trabalho, é o cuidado terapêutico enquanto um modo diferenciado de cuidar pela equipe de enfermagem, com alta competência técnica, compromisso ético e percepção de uma práxis transformadora e emancipadora. Os instrumentos de trabalho são entendidos como os meios entre o objeto e a força de trabalho (equipe de enfermagem). Por sua vez, esses instrumentos são projetados para garantir a existência do produto final, isto é, o objeto de trabalho transformado pelo cuidado terapêutico ${ }^{(6)}$.

A atenção básica representa um campo de atuação privilegiado em termos de investimentos das políticas públicas a partir da institucionalização do Sistema Único de Saúde (SUS). Ou seja, foram introduzidos, a partir desse marco, programas inovadores e estratégicos para a mudança no modelo assistencial do SUS ${ }^{(7)}$. Sendo assim, a atenção básica é caracterizada como um conjunto de ações, de caráter individual ou coletivo, focados na promoção da saúde, prevenção de agravos, tratamento e reabilitação ${ }^{(8)}$. Seu conceito surgiu e se consolidou no contexto de ampliação da descentralização do SUS e na mudança do modelo assistencial, com o intuito de destacar as ações preventivas e de enfrentamento dos determinantes de saúde ${ }^{(9)}$.

A ênfase do trabalho na atenção básica encontra-se na atuação em equipe multiprofissional, que consiste em uma modalidade de trabalho coletivo que se configura na relação recíproca entre as múltiplas intervenções técnicas e a interação dos agentes de diferentes áreas profissionais ${ }^{(10)}$. Para a atuação em equipe faz-se necessário que cada profissional conheça os elementos de seu processo de trabalho, bem como invista no planejamento de objetivos comuns aos demais profissionais face às necessidades dos usuários.

Apesar de passados mais de vinte anos da constitucionalização do SUS, ainda é possível constatar que o sistema enfrenta desafios importantes para sua implantação efetiva, como a questão do financiamento e suporte na gestão das ações de saúde, suporte de materiais e equipamentos para garantir uma assistência de qualidade, número de profissionais adequados às demandas da população, remuneração apropriada para o profissional da saúde, dentre outros problemas ${ }^{(11)}$. Frente a essa problemática, a qualidade de vida dos profissionais da saúde merece ser vislumbrada, já que conviver com essas situações pode ser desgastante à saúde do trabalhador, o que muitas vezes traduz-se pelo sofrimento ou mesmo adoecimento do corpo e da mente.

Tendo isso em vista, o presente estudo objetivou conhecer a percepção dos enfermeiros que atuam nas unidades básicas de saúde (UBS) de Pelotas, Rio Grande do Sul (RS), sobre a sua QVT. Essa preocupação se justifica pela atual conjuntura, que coloca o profissional que atua na atenção básica encarregado de sustentar muitas das lacunas do sistema, incluindo recursos insuficientes de trabalho, propostas políticas sem continuidade, pessoas despreparadas para atuar com base nos princípios do SUS, população descontente e até revoltada, dentre outras questões que repercutem diretamente no cotidiano laboral dos trabalhadores.

\section{METODOLOGIA}

Tratou-se de um estudo qualitativo, exploratório e descritivo. A escolha dos sujeitos se deu de forma intencional e por acessibilidade, desta forma, foram entrevistados sete enfermeiros atuantes em UBS de Pelotas-RS. A cidade conta atualmente com 51 UBS, das quais seis estão ligadas às 
universidades e dezessete delas contam com equipes de Estratégia de Saúde da Família, que atendem aproximadamente $30 \%$ da população.

A abordagem aconteceu no próprio local de trabalho, sendo utilizado um roteiro semiestruturado. As falas foram gravadas em áudio, sendo respeitados os princípios éticos da pesquisa, como preconiza a Resolução 196/96, do Conselho Nacional de Saúde. Os objetivos da investigação e o caráter espontâneo da participação foram esclarecidos aos participantes quando da apresentação do Termo de Consentimento Livre e Esclarecido. O projeto teve sua aprovação prévia pelo comitê de ética e pesquisa da Faculdade de Enfermagem da UFPel, sob o número 20/2009.

O material originado das falas transcritas foi tratado mediante análise temática ${ }^{(12)}$. Dessa análise emergiram os temas: (1) Condições de trabalho; (2) Amparo dos gestores; (3) Relações interpessoais e (4) Prazer com a atividade de cuidar.

Para melhor apresentação dos resultados, foram extraídos e utilizados recortes das falas dos sujeitos do estudo. A fim de preservar o anonimato dos participantes, utilizaram-se códigos de identificação com a letra E para nomeá-los, seguida do número correspondente à ordenação das entrevistas (E1, E2).

\section{RESULTADOS E DISCUSSÃO}

A qualidade de vida dos enfermeiros que trabalham na atenção básica de Pelotas-RS foi avaliada pelos participantes como resultante de fatores relacionados às condições laborais, bem como às relações sociais constituídas e constituintes do trabalho. A seguir esses fatores são apresentados e discutidos.

\section{Condições de Trabalho nas Unidades Básicas de Saúde}

As condições de trabalho foram muito enfocadas pelos trabalhadores entrevistados, visto que todos salientaram a realização de um trabalho de pior qualidade devido à falta de condições adequadas para o trabalho. A convivência com materiais sucateados, falta de medicamentos e equipamentos foram fatores apontados como determinantes na qualidade de vida, pelo prejuízo que isso traria à assistência prestada e à autopercepção do próprio labor.

Os materiais estão bastante sucateados, a questão da manutenção é complicada, muitas vezes tu não tens um esfigmomanômetro, não tens um estetoscópio em qualidade boa, muitas vezes não tens uma cadeira para se sentar. Às vezes eu não consigo realizar o trabalho que gostaria por falta de materiais. (E1)

Posso dizer que minha qualidade de vida no trabalho está comprometida porque a gente não tem material, não consigo desempenhar minhas funções. (E5)

As limitações vivenciadas pelos enfermeiros face à inadequação de recursos para o desempenho das atividades profissionais também foram apontadas em outro estudo ${ }^{(13)}$, revelando a interferência desse aspecto na organização do trabalho dos serviços de atenção básica. Frente a isso, os profissionais experimentam sentimentos de frustração por não conseguirem alcançar a qualidade da atenção que gostariam.

Além disso, os entrevistados salientam que em decorrência da grande demanda, o trabalho passa a ser focado em dar conta do número de atendimentos e não na qualidade da atenção dispensada. Assim, os enfermeiros sentem que acabam realizando suas obrigações automaticamente e não desenvolvem o cuidado como desejado e de acordo com as prerrogativas do SUS, que preconizam o atendimento integral e humanizado.

Há sobrecarga de trabalho, porque muitas vezes tu não consegues nem pensar o teu fazer, na verdade tu te tornas um tarefeiro. (E1)

Sobrecarga de muitos atendimentos, até porque o nosso tipo de trabalho deveria ser um trabalho mais focado na qualidade, mas às vezes você tem que ficar na quantidade. (E2)

Nota-se que, apesar da proposta do SUS primar pelo investimento em ações de promoção e prevenção da saúde, os profissionais ainda atuam sob o enfoque curativo e com atividades fragmentadas, uma vez que as condições de trabalho não propiciam o tempo, o espaço e as circunstâncias necessárias para o desenvolvimento do cuidado integral.

Sobre essa questão, cabe mencionar que o conflito vivenciado pelo trabalhador pode emergir justamente pelo fato de que a organização prescrita para o trabalho seja inalcançável no mundo real ${ }^{(14)}$. Ou seja, espera-se do trabalhador uma produção para a qual não Ihe são dadas as condições mínimas de trabalho, o que afeta a própria expectativa do profissional, bem como dos consumidores desses serviços.

Outro fator ressaltado pelos participantes do estudo foi a remuneração, que adquire um significado importante para o enfermeiro, já que se constitui como fonte de motivação para o trabalho e, consequentemente, para a qualidade de vida. É por meio do salário que as pessoas atendem suas necessidades, concretizam seus desejos e planejam boa parte de suas vidas. A remuneração dos profissionais da enfermagem tem sido descrita como insuficiente, principalmente frente às responsabilidades assumidas ${ }^{(15,16)}$.

Embora não seja o único benefício proporcionado pelo trabalho, o ganho financeiro oriundo do esforço laboral é convertido em vantagens para a vida do trabalhador ${ }^{(17)}$ e sua insuficiência não agrada aos profissionais entrevistados, como pode ser visto nos falas a seguir descritas.

A gente ganha pouco, é uma dificuldade da nossa categoria. (E3)

A remuneração tem que te proporcionar o mínimo de qualidade de vida, tu tem que ter condições de lazer, de moradia, de vestuário, de aperfeiçoamento, isso é o teu salário que tem que proporcionar [...] no momento que isso não acontece, te frustra bastante, porque apesar de desempenhar a tua função, tu não consegue ter uma vida que seja agradável. (E6) 
Assim, os enfermeiros justificaram a relevância da remuneração para a qualidade de vida. Segundo eles, as possibilidades que um salário digno pode proporcionar em termos de conforto e acesso a bens de consumo interfere na qualidade de vida.

Cabe ainda mencionar a preocupação dos entrevistados com o seu próprio acesso à assistência para a saúde. Eles referiram que a baixa remuneração impossibilita o acesso a serviços pagos de saúde, como pode ser conferido na seguinte fala:

Inclusive a questão do acesso a serviços de saúde nas situações que o SUS não te oferece, isso é importante na nossa qualidade de vida. (E6)

Ainda, a baixa remuneração origina acúmulo de vínculos empregatícios e consequentemente, excesso de horas trabalhadas e pouco tempo para as demais atividades da vida, como o lazer e a recreação ${ }^{(18)}$. Em contrapartida, o mercado de trabaIho tem se tornado mais exigente mediante o avanço tecnológi$\mathrm{co}$, requerendo um profissional mais qualificado, mais especializado. Possivelmente, esses fatores têm prejudicado não só a vida pessoal, mas também a interação familiar do enfermeiro ${ }^{(3)}$.

A baixa remuneração tem se tornado fator de descontentamento e desânimo por não atender às necessidades de sobrevivência com decência e conforto, levando os profissionais da enfermagem a assumirem mais de um vínculo empregatício para obter melhores condições de vida. Essas condições acarretam uma carga horária de trabalho exaustiva, desgaste físico e psíquico a estes trabalhadores ${ }^{(16)}$.

A remuneração tem um papel fundamental, se ela fosse um pouco melhor no Brasil, certamente os enfermeiros se realizariam mais profissionalmente, até por que não precisaria correr atrás de um segundo ou terceiro emprego. (E7)

O excesso de horas trabalhadas, devido à soma de postos de trabalho, traz cansaço e restringe ao aproveitamento da vida em família e em sociedade. Nessas situações, o enfermeiro ainda precisa dar conta de demandas laborais diversas, incluindo escassos intervalos para a alimentação e o descanso.

Assim o profissional não recebe um salário justo, levando-se em conta as horas trabalhadas, os deveres impostos e a escassez de pessoal, se fazendo necessário adequá-lo às habilidades e ao conhecimento do profissional, podendo, estes fatores influenciarem na permanência ou abandono da profissão $^{(17)}$.

Porém, não se pode restringir a dignificação do trabalho exclusivamente às questões salariais, embora sejam estas questões cruciais ${ }^{(17)}$, dessa forma, alguns participantes diminuíram a importância da remuneração, afirmando que a qualidade do atendimento não deve ser condicionada ao salário que o trabalhador recebe. As falas que seguem trazem à tona essa questão, no entanto, é possível ainda assim constatar os benefícios da remuneração para a qualidade de vida.

Eu faço meu trabalho porque eu gosto, não o faço por dinheiro porque se não eu não estaria trabalhando nesse tipo de trabalho. (E2)
Se tu te submetes a fazer um bom trabalho, independente da remuneração tu tens que fazer um bom trabalho, mas se tu ganhares mais, tu és valorizado, isso é um incentivo, é teu mérito, tu te sentes muito melhor. (E4)

Enquanto existem pessoas que se sentem motivadas pelo sucesso financeiro, outras se sentem felizes fazendo algo que gostam, desde que isso lhe dê o retorno financeiro mínimo necessário para uma sobrevivência digna ${ }^{(17)}$.

Por outro lado, um participante salientou que, embora mal remunerado, há o fator estabilidade que pode ser considerado como ponto positivo para a QVT. O benefício da estabilidade conferida pelo vínculo empregatício também foi apontada em outro estudo ${ }^{(17)}$, revelando que, apesar dos enfermeiros estarem insatisfeitos com os salários oferecidos pelas instituições, estas representariam oportunidades para colocar em prática os ensinamentos aprendidos na Universidade, para atuar em programas de saúde estruturados e, ainda, pela questão da estabilidade no emprego, através de concursos públicos.

É uma das poucas coisas que a gente tem de vantagem é a questão da estabilidade. (E6)

Na contemporaneidade, o desemprego tem sido fator ameaçador da vida humana, por isso, o trabalhador acaba se submetendo a situações indesejadas ou até nocivas para continuar empregado. Diante das condições, por vezes adversas, com as quais o profissional se depara, cabe salientar que não há neutralidade do trabalho em relação à saúde do trabalhador, uma vez que este poderá potencializar a saúde ou o adoecimento ${ }^{(14)}$.

\section{Falta de amparo dos gestores}

Os enfermeiros abordados mencionaram a dificuldade no planejamento e desenvolvimento de seu trabalho devido ao suporte insuficiente por parte dos gestores, o que acaba implicando na QVT e, por consequência, no serviço prestado aos usuários. Essa situação leva à diminuição da produtividade e à baixa qualidade da assistência prestada à comunidade, gerando um sentimento de insatisfação por parte de todos os envolvidos, como pode ser visto no trecho que segue:

$\mathrm{Na}$ verdade a gente carece muito de retaguarda de chefia, então isso te deixa um pouco insatisfeita (...) bom seria ter um amparo naquilo que tu planejas e desejas fazer, é uma pena que aqui na UBS o suporte do município é meio 'capenga' [deficiente] e não favorece o nosso trabalho. (E1)

Nota-se que o trabalhador sente-se desassistido em relação ao apoio que recebe de seus gestores e mesmo assim tem o desafio de colocar em prática os princípios de humanização e integralidade. Frente a isso, questiona-se o compromisso dos gestores na concretização desses princípios no contexto estudado.

Cabe mencionar que o ato de gerenciar requer do indivíduo não apenas competência, mas, acima de tudo, habilidade política para o planejamento de recursos financeiros 
e de pessoas conforme a necessidade de cada contexto. $\mathrm{O}$ gerenciamento do setor público constitui uma das primeiras ferramentas de controle da economia do país e o gestor é o responsável por esta atividade ${ }^{(19)}$.

Além disso, as entrevistas revelaram que a desvalorização profissional junto ao precário reconhecimento por parte dos gestores é outro fator desmotivante e estressante no trabalho realizado pelo enfermeiro e sua equipe, pois resulta em profissionais frustrados e desanimados com suas perspectivas de trabalho.

As organizações reduzem o impacto dos estressores quando oferecem autonomia ao enfermeiro, com o respaldo às decisões tomadas pelos profissionais, sendo o não reconhecimento do profissional um estressor caracterizado em grande parte dos estudos ${ }^{(20)}$.

Às vezes a gente não é valorizado pelo que faz. Às vezes tu tenta fazer um bom trabalho na ponta, mas tu não tens o apoio lá de cima. (E2)

Na medida em que os trabalhadores não recebem apoio da gestão, eles se sentem desmotivados pelo não reconhecimento ao seu esforço e às consequências da (des)qualificada assistência prestada à população. A valorização humana é uma fonte de motivação, pois proporciona espaço e incentivo ao trabalhador, podendo gerar crescimento pessoal e profissional(21).

\section{Importância das relações interpessoais nas equipes das UBS}

Os enfermeiros, como sujeitos sociais, estabelecem relações interpessoais em sua prática profissional. Essas relações podem se caracterizar por apoio e cordialidade, ou mesmo repressão e rejeição, ambas com implicações em suas atividades ${ }^{(22)}$, bem como sobre a QVT, como mencionado pelos entrevistados.

O relacionamento com a equipe que trabalho interfere, se ele é ruim a qualidade de vida no trabalho também será péssima (...) relação profissional é empatia e respeito, se não tem isso não tem relação profissional nenhuma e sim, é um grupo de pessoas que se suportam. (E5)

Sair de casa e vir trabalhar pensando que eu vou para um lugar legal, onde vai ter pessoas que eu gosto, me satisfaz. (E2)

O trabalho em equipe depende do esforço de cada um dos sujeitos envolvidos, objetivando o mesmo fim. O compromisso com o cuidado do outro e o companheirismo entre colegas são a alavanca principal para o desenvolvimento de um trabalho qualificador na enfermagem. Torna-se importante valorizar as relações interpessoais no ambiente de trabalho, cuidando de si e do outro ${ }^{(23)}$ com vistas à QVT.

Os valores, os fundamentos, os sentimentos e as ações dos integrantes da equipe refletem-se na prática. Assim, o ambiente passa a ser espelho das relações pessoais e sociais ${ }^{(24)}$.

Nesse sentido, cabe ressaltar que as relações com a chefia e a comunidade também interferem no desempenho e satisfação do profissional enfermeiro, uma vez que a subjetividade implicada na interação constante entre trabalhador e objeto do trabalho influencia a organização do trabalho. Tratam-se, portanto, de interações laborais que definem a QVT.

Quando a gente não consegue ter um diálogo com a chefia é complicado e interfere diretamente na minha qualidade de vida. (E5)

A gente tem que conseguir melhorar o ambiente, as relações entre patrão-empregado, o vínculo que se cria com o cliente, com a comunidade. (E7)

Dessa forma, os enfermeiros entrevistados expressaram que as relações interpessoais com a chefia, bem como com cliente e comunidade, são influentes na QVT. Diante disso, compreende-se que seja no âmbito das relações cotidianas de trabalho que se fortalecem ou se destroem os vínculos humanos. Por conseguinte, a QVT depende das características desses vínculos, que podem estimular relações horizontais, promotoras da co-gestão e co-autonomia dos sujeitos, ou ainda, relações verticalizadas, caracterizadas pelo autoritarismo e subordinação.

\section{Prazer com a atividade de cuidar}

É através do trabalho que se alcança a realização e satisfação pessoal, a busca da felicidade, o preenchimento da vida com atos significativos para si e para os outros. Enfim, significa a identificação, o reconhecimento dentro do contexto social, a inclusão na sociedade como um indivíduo produtivo ${ }^{(17)}$.

De acordo com esse conceito, a maioria dos participantes da pesquisa referiu a realização pessoal como fundamental para a QVT, o que também foi identificado em outra pesquisa (25). Desta forma, destaca-se na presente investigação que os enfermeiros atribuíram a sua sensação de utilidade à recompensa moral pelo esforço dispendido no trabalho.

Eu acho que o trabalho é fundamental, assim, principalmente para a gente se sentir útil, ter alguma coisa que tu faças e que seja teu, que tenha algum beneficio para outra pessoa. (E6)

O trabalho, ele acrescenta muito, porque a gente se realiza e se realizando profissionalmente a gente vai se realizando do ponto de vista humano, pessoal. (E7)

Além disso, os entrevistados ainda relataram que a atividade de cuidar proporciona satisfação, o que foi mencionado como sendo um atributo importante do labor do enfermeiro face ao longo tempo dispensado para o trabalho.

Eu faço o que gosto, a gente fica maior tempo do dia no trabalho, nós ficamos oito horas aqui dentro trabalhando, eu gosto de ser enfermeiro, gosto de fazer o que eu faço trabalhar com os pacientes, atender as dificuldades e necessidades deles. (E4)

Eu acho que qualidade de vida é me sentir feliz no que eu faço, é eu gostar do que faço. (E2) 
Conforme já discutido em outro estudo ${ }^{(24)}$, o nível de satisfação profissional vem tornando-se fator essencial, determinante e discutível para melhor entendimento do cuidado. $\mathrm{O}$ cuidar deve ser compreendido como a realização de ações na enfermagem considerando-se inevitável à satisfação de um conjunto de necessidades tanto da clientela, como dos integrantes da equipe de enfermagem que executam este cuidado, envolvendo interação e autonomia.

Além do exposto, acredita-se que o trabalhador consiga satisfação com o ato de cuidar devido ao valor simbólico da atividade $^{(26)}$, ou seja, o orgulho conquistado pela realização de uma tarefa que, antes de tudo, pressupõe o bem ao próximo, atribuindo benefícios na ordem da subjetividade. Dessa maneira, crê-se que, quando reconhecido o cuidado terapêutico como finalidade do processo de produção, o prazer oriundo dessa perspectiva pode vir a representar um alicerce à QVT do enfermeiro.

\section{CONSIDERAÇÕES FINAIS}

O estudo realizado possibilitou compreender que a QVT é alcançada a partir da obtenção da satisfação e realização pessoal, profissional e social, que por sua vez emergem do contexto do serviço de saúde. Para os participantes da investigação, as condições inadequadas para o trabalho, a desvalorização profissional, o suporte insuficiente dos gestores e a baixa remuneração são fatores prejudiciais da QVT dos trabalhadores que atuam na atenção básica de Pelotas.

Contudo, os sujeitos da pesquisa ressaltaram as boas relações interpessoais estabelecidas, principalmente entre profissionais, como fontes geradoras da QVT. Ainda, foi salientado o benefício de se gostar da atividade desempenhada, o que eles acreditam interferir no desempenho profissional e na organização do trabalho.

Os resultados assinalaram a necessidade da participação ativa dos gestores nos desafios vivenciados no cotidiano laboral dos enfermeiros que atuam na atenção básica. Além disso, a remuneração se destacou dentre os aspectos implicados na melhoria da QVT e do serviço prestado à comunidade.

Diante do exposto, ressalta-se a importância da constante avaliação do processo de trabalho na atenção básica para resgatar o sentido do trabalho, bem como, potencializar o profissional enfermeiro como transformador da sua realidade. Como limitação do estudo, menciona-se a exclusiva participação dos profissionais enfermeiros, uma vez que a discussão poderia ser ampliada para uma abordagem multiprofissional. Entende-se que essa limitação instiga novas investigações.

\section{REFERÊNCIAS}

1. Brasil. Lei no 8.080, 19 de setembro de 1990. Lei Orgânica da Saúde. Diário Oficial da União 20 set 1990.

2. Organização Mundial da Saúde [homepage na internet]. Versão em português dos instrumentos de avaliação de qualidade de vida (whoqol) 1998. [acesso em 07 nov 2010]. Disponível em: http://www.ufrgs.br/psiq/whoqol84.html.

3. Araújo GA, Soares MJGO, Henriques MERM. Qualidade de vida: percepção de enfermeiros numa abordagem qualitativa. Rev Eletrônica Enferm [periódico na internet] 2009; [acesso em 09 out 2010];11(3):635-41. Disponível em: http://www.fen.ufg.br/revista/v11/n3/pdf/v11n3a22.pdf.

4. Lacaz FAC. Qualidade de vida no trabalho e saúde/doença. Ciênc Saúde Coletiva 2000;5(1):151-61.

5. Beck CLC. O sofrimento do trabalhador: da banalização a resignificação ética na organização da enfermagem. Florianópolis: UFSC; 2001.

6. Thofehrn MB, Leopardi MT. Teoria dos Vínculos profissionais: formação de um grupo de trabalho. Pelotas: Editora Universitária/UFPel; 2009.

7. Macinko J, Almeida C, Oliveira E. Avaliação das características organizacionais dos serviços de atenção básica em Petrópolis: teste de uma metodologia. Saúde Debate 2003;27(65):243-56.

8. Brasil. Ministério da Saúde. Portaria nº 3.925, de 13 de novembro de 1998. Aprova o Manual para Organização da Atenção Básica no Sistema Único de Saúde. [portaria na internet]. Diário Oficial da União 17 nov 1998. [acesso em 11 out 2010]. Disponível em: http://dtr2004.saude. gov.br/dab/docs/legislacao/ portaria3925_13_11_98.pdf.

9. Levcovitz E, Lima LD, Machado CV. Política de saúde nos anos 90: relações intergovernamentais e o papel das Normas Operacionais Básicas. Ciênc Saúde Coletiva 2001;6(2):269-91.

10. Peduzzi M. Equipe multiprofissional em saúde: conceito e tipologia. Rev Saúde Pública 2001;1(35):103-9.

11. Cohn A. A reforma sanitária brasileira após 20 anos do SUS: reflexões. Cad Saúde Pública 2009; 25(7):1614-9.

12. Minayo MC. O desafio do conhecimento: pesquisa qualitativa em saúde. 11. ed. São Paulo: HUCITEC; Rio de Janeiro: ABRASCO; 2008.

13. David HMSL, Mauro MYC, Silva VG, Pinheiro MAS, Silva FH. Organização do trabalho de enfermagem na atenção básica: uma questão para a saúde do trabalhador. Texto \& Contexto Enferm 2009;18(2):206-14.

14. Dejours C. Subjetividade, trabalho e ação. Rev Prod 2004;14(3):27-34.

15. Nóbrega MM, Lopes DN, Dantas HF, Perez VLAB. O ser enfermeiro num contexto transcultural. Rev Bras Enferm 1996;49(3):399-408.

16. Júnior JHVL, Ésther $A B$. Transições, prazer e dor no trabalho de enfermagem. Rev Adm Empresas [periódico na internet]. 2001 [acesso em 10 set 2010];41(3):20-30. Disponível em: http://www2.ghc.com.br/gepnet/docscursos/ gestao/gestaomaterialdidatico33.pdf . 
17. Batista AAV, Vieira MJ, Cardoso NCSC, Gysella RP. Fatores de motivação e insatisfação no trabalho do enfermeiro. Rev Esc Enferm USP 2005;39(1):85-91.

18. Schmidt DRC, Dantas RAS. Qualidade de vida no trabalho de profissionais de enfermagem, atuantes em unidades do bloco cirúrgico, sob a ótica da satisfação. Rev Latinoam Enferm 2006;14(1):54-60.

19. Miranda DB, Guimarães IG, Alves ED. Representações Sociais da descentralização do SUS: Perspectivas dos gestores municipais de saúde de Goiânia, Brasil. Rev Baiana Saúde Pública 2009; 33(3):349-360.

20. Guido LA. Stress e Coping entre enfermeiros de centro cirúrgico e recuperação anestésica. São Paulo. Tese [Doutorado em Enfermagem]- Escola de Enfermagem/USP; 2003.

21. Beck CLC, Lisbôa RL, Tavares JP, Silva RM, Prestes FC. Humanização da assistência de enfermagem: percepção de enfermeiros nos serviços de saúde de um município.
Rev Gaúch Enferm 2009;30(1):54-61.

22. Santos MCL, Braga VAB, Fernandes AFC. Nível de satisfação dos enfermeiros com seu trabalho. Rev Enferm UERJ 2008;16(1):101-5.

23. Baggio MA. Relações humanas no ambiente de trabalho: o (des)cuidado de si do profissional de enfermagem. Rev Gaúch Enferm 2007;28(3):409-15.

24. Vitória R, Ladeia LF, Porto IS. A equipe de enfermagem e Maslow: (in)satisfações no trabalho. Rev Bras Enferm 2006;59(4):565-8.

25. Salles PEM, Federighi WJ. Qualidade de vida no trabaIho (QVT): a visão dos trabalhadores. Rev Mundo Saúde 2006;30:263-78.

26. Dal Pai D, Lautert L. O trabalho em urgência e emergência e a relação com a saúde das profissionais de enfermagem. Rev Latinoam Enferm 2008;16(3):439-44. 